the very important shift from the librarian as custodian to the librarian as bookman, bibliophile, and man-of-letters, to the present librarian as administrator and specialist in management. Yet there is probably no single development more important than this in altering the complexion of the profession of librarianship.

While these are negative points, and the study runs counter to the approach to library history for which this reviewer has long argued, the volume, based on a doctoral dissertation at Stanford, is carefully written and documented and should serve as a source of information to students of university library history.-Jesse H. Shera, School of Library Science, Western Reserve University.

\section{Subject Classification: A Comment}

Anent Dr. Mortimer Taube's very informative and entertaining review, in the October I 953 issue of $C \Xi^{\circ} R L$ of Henry Evelyn Bliss' Bibliographic Classification, I think it is about time that someone came to the defense of shelf classifications in libraries. They have been almost generally maligned these past few years with hardly a voice raised in protest. I am not speaking of any shelf classification in particular, since librarians as a whole seem to feel the same way about the particular one they have fallen heir to, i.e., that they are poor things, but mine, and after all so much better than the one that belongs to my neighbor. Despite the fact that the general impression seems to exist that shelf classification is a dead dog at which everyone can take an occasional kick, they are still very vigorously alive and likely to remain so for a considerable length of time. Studies have pointed out to the point of ennui that subject bibliographies, card catalogs, "coordinate indexes," etc. are "better" and "more effective" than shelf classifications, but fail to make clear that this sort of comparison entirely missed the point that shelf classifications cannot be expected to serve the same purposes as these other methods of information control. Shelf classification is at best only an auxiliary method of organizing materials for use, and because of the shortcomings of the other methods it is a most necessary auxiliary. Since location symbols are necessary in any case, shelf classification serves a double purpose and are certainly more desirable than location symbols that have no subject significance. As a perennial browser I can only regard with horror the present advocacy of the elimination of shelf classification. I have a suspicion as well that many of the people who use libraries, who to date seem to have had a very small voice in the controversy, would feel the same way about it.

It should seem apparent to anyone that alphabetic and classified arrangements which Dr. Taube has gratuitously thrown together under that much maligned and ill-used term "semantics" are not the same thing at all. By framing his case with a very judicious choice of terms, he has made them appear equivalent techniques with the implication that it is a matter of complete indifference or pure whim which arrangement one chooses. A selection of any other group of terms almost at random will indicate that this is not so, e.g.:

$\begin{array}{lc}\text { Bicycles } & \text { Cycles } \\ \text { Cycles } & \text { Unicycles } \\ \text { Guitarists } & \text { Bicycles } \\ \text { Musicians } & \text { Tricycles } \\ \text { Tricycles } & \text { Musicians } \\ \text { Unicycles } & \text { Violinists } \\ \text { Violinists } & \text { Guitarists } \\ \text { Zither players } & \text { Zither players }\end{array}$

The basic difference between the two methods, of course, is that whereas both may be embodied in the form of word symbols, classifications are not bound by the symbols used to embody the meaning, while in the alphabetic system the word symbols are the basis of the arrangement. Dr. Taube does his cause no service by appearing to confuse them.

Classification is a process that is inevitable no matter how one may choose to disguise it, and by the nature of the case it is especially inevitable in libraries. A library classifies materials in the process of ordering them in conformity with its acquisitions policies and in dividing them in subject departmentalized libraries. Despite the animadversions of the scholars, shelf classifications will continue to be used for a long time in libraries, and in view of the current and continuing practice, the whole discussion sometimes seems somewhat academic.-David $A$. Kronick, Reference Section, Armed Forces Medical Library. 